\title{
O alçamento e o abaixamento da pretônica /O/ nos Atlas Linguísticos do Ceará, Paraíba e Bahia
}

\author{
The raising and lowering of the pretonic $/ O$ / in the \\ Linguistic Atlas of Ceará, Paraíba and Bahia
}

\author{
Patrícia Jéssica Rocha Silva ${ }^{1}$ \\ Aluiza Alves de Araújo² \\ Rakel Beserra de Macedo Viana ${ }^{3}$
}

\begin{abstract}
RESUMO: Este trabalho pretende investigar as regras de alçamento e abaixamento da vogal média pretônica /O/, à luz da Sociolinguística Variacionista (LABOV, 2008; WEINREICH; LABOV; HERZOG, 2006), analisando a influência dos fatores sociais sexo (feminino e masculino), faixa etária (de 20 a 60 anos e acima de 60 anos), escolaridade (não alfabetizados e alfabetizados) e localidade (Ceará, Paraíba e Bahia) que favorecem ambas as regras. Para tanto, foram observadas as ocorrências das variantes /o/, / / e / $\mathbf{2} /$ presentes nas cartas fonéticas dos Atlas Linguísticos da Bahia (ROSSI; ISENSÉE; FERREIRA, 1963), da Paraíba (ARAGÃO; MENEZES, 1984) e do Ceará (BESSA, 2010). Os dados foram coletados, codificados e submetidos às análises estatísticas do programa Goldvarb $X$. Os resultados revelaram que há uma predominância da regra de elevação no Ceará e na Bahia em oposição à manutenção da pretônica /O/, já na Paraíba prevalece a regra de abaixamento desta pretônica.
\end{abstract}

PALAVRAS-CHAVE: Vogal média pretônica /O/. Sociolinguística Variacionista. Atlas Prévio dos Falares Baianos - APFB. Atlas Linguístico da Paraíba - ALP. Atlas Linguístico do Estado do Ceará - ALECE.

RESUMEN: Este trabajo pretende investigar las reglas de elevación y depresión de la vocal media pretónica /O/, a la luz de la Sociolingüística Variacionista (LABOV, 2008, WEINREICH, LABOV, HERZOG, 2006), analizando la influencia de los factores sociales sexo (femenino y masculino), grupo de edad (de 20 a 60 años y superiores a 60 años),

${ }^{1}$ Graduanda em Letras Português na Universidade Estadual do Ceará (UECE) e bolsista de Iniciação Científica, vinculada ao projeto de pesquisa intitulado $A$ variação das pretônicas /e/ e /o/ nos Atlas Linguísticos estaduais do Brasil: uma fotografia sociolinguística, sob a orientação da professora Aluiza Alves de Araújo.

2 Doutora e mestre em Linguística pela Universidade Federal do Ceará (UFC). Graduada em Letras pela Universidade Estadual do Ceará (UECE). Professora adjunta K da graduação em Letras e do curso de Pós-Graduação em Linguística Aplicada (PosLA) do Centro de Humanidades $(\mathrm{CH})$ da UECE. Atua na área de Letras com ênfase em Linguística, Sociolinguística e Dialetologia. É coordenadora do projeto Retratos sociolinguísticos de aspectos fonológicos, morfológicos e sintáticos do falar de Fortaleza - CE.

3 Mestranda em Linguística Aplicada pelo Programa de Pós-Graduação em Linguística Aplicada da Universidade Estadual do Ceará - UECE. Professora de Língua Portuguesa e Inglesa da SEDUC/CE desde 2010. 
escolaridad (no alfabetizados y alfabetizados) y localidad (Ceará, Paraíba y Bahía) que favorecen ambas reglas. Para ello, se observaron las ocurrencias de las variantes [ $\square$ ], $[\square]$ e $[\diamond]$ presentes en las cartas fonéticas de los Atlas Linguísticos de Bahía (ROSSI, ISENSÉE, FERREIRA, 1963), de Paraíba (ARAGÃO; MENEZES, 1984) y de Ceará (BESSA, 2010). Los datos fueron recolectados, codificados y sometidos a los análisis estadísticos del programa Goldvarb $X$. Los resultados revelaron que hay una predominancia de la regla de elevación en Ceará y Bahía en oposición al mantenimiento de la pretónica /O/, ya en Paraíba prevalece la regla de depresión de esta pretónica.

PALABRAS CLAVE: Vocal Pretónica /O/. Sociolingüística Variacionista. Atlas Prévio dos Falares Baianos - APFB. Atlas Linguístico da Paraíba - ALP. Atlas Linguístico do Estado do Ceará - ALECE.

ABSTRACT: This work intends to investigate the rules of raising and lowering the pretonic average vowel /O/, in the light of Variationist Sociolinguistics (LABOV, 2008; WEINREICH; LABOV; HERZOG, 2006), analyzing the influence of the social factors sex (female and male), age (from 20 to 60 years and over 60 years), schooling (non literate and literate) and locality (Ceará, Paraíba and Bahia) favoring both rules. For this, the occurrences of the variants $/ \square /, / \nabla /$ and /2/ were present in the phonetic charts Linguistic Atlas of Bahia (ROSSI, ISENSÉE, FERREIRA, 1963), Paraíba (ARAGÃO, MENEZES, 1984) and Ceará (BESSA, 2010). The data were collected, coded and submitted to the statistical analysis of the Goldvarb X program. The results revealed that there is a predominance of the elevation rule in Ceará and Bahia as opposed to the maintenance of the pretonic $/ \mathrm{O} /$, whereas in Paraíba the lowering rule prevails this pretonic.

KEYWORDS: Pretonic average vowel /O/. Sociolinguistic Variation. Atlas Prévio dos Falares Baianos - APFB. Atlas Linguístico do Estado do Ceará - ALECE. Atlas Linguístico da Paraíba - ALPB.

\section{Introdução}

A variação da vogal média /O/ em contexto pretônico é o objeto de estudo deste trabalho. Nele analisamos, à luz da Sociolinguística Variacionista defendida por Labov (2008) e Weinreich, Labov e Herzog (2006), as ocorrências das pretônicas posteriores vogal alta $/ \diamond /$, vogal média alta $/ \square / \mathrm{e}$ vogal média baixa /2/ registradas nas cartas fonéticas presentes no Atlas Linguístico do Estado do Ceará (BESSA, 2010), no Atlas Linguístico da Paraíba (ARAGÃO; MENEZES, 1984) e no Atlas Prévio dos Falares Baianos (ROSSI; ISENSÉE; FERREIRA, 1963).

Os fatores considerados nesta pesquisa são os sociais (sexo, idade, escolaridade e localidade). O propósito desse estudo é observar quais desses 
fatores favorecem a aplicação das regras de alçamento [ $\bullet$ ], abaixamento [2] e manutenção $[\square]$ em ambiente pretônico.

Para isso, analisamos um corpus de 472 informantes, sendo 265 informantes pertencentes ao banco de dados do Atlas Linguístico do Estado do Ceará (ALECE), 107 informantes do Atlas Linguístico da Paraíba (ALPB) e 100 informantes do Atlas Linguístico dos Falares Baianos (APFB). Como a faixa etária é diferente entre os três atlas, decidimos controlar duas faixas etárias (faixa 1 - de 20 a 60 anos; faixa 2 - acima de 60 anos). Também há divergências entre os atlas com relação à escolaridade, por isso, estabelecemos apenas dois níveis de escolaridades (não alfabetizados e alfabetizados). Quanto ao fator localidade, decidimos controlar em três pontos (Ceará, Paraíba e Bahia) para o controle desta pesquisa.

Para o referencial teórico, tivemos dificuldades em localizar estudos sobre a variação da vogal média pretônica /O/ que utilizassem como corpus o banco de dados dos Atlas Linguísticos dos estados do Ceará, Paraíba e Bahia, conforme utilizamos em nossa pesquisa. Em vista disso, selecionamos alguns estudos recentes (PAIM; ANJOS, 2015; CARMO; TENANI, 2013; CRUZ; SOUZA, 2013; RAZKY; LIMA; OLIVEIRA, 2012) que investigaram a variação das vogais médias pretônicas utilizando o aporte teórico metodológico da Sociolinguística Variacionista (LABOV, 2008; WEINREICH; LABOV; HERZOG, 2006), contudo, buscaremos apresentar os resultados concernentes ao nosso objeto de estudo (a variação da vogal média pretônica $/ O /$ ).

Observando os estudos mencionados, presumimos que os não alfabetizados tendem a fazer uso da variante alta [ $\bullet$ e que as mulheres fazem mais uso da variante fechada [ $\square]$. Já os homens são aliados da variante aberta [2] e os mais escolarizados beneficiam a variante fechada [0]. Também supomos que a variável social localidade influencia na realização da variante aberta [0].

Ademais, estruturamos nosso trabalho com algumas seções além desta breve introdução. Apresentamos alguns estudos recentes sobre a variação da pretônica /O/ e uma breve apresentação da Teoria Variacionista. Em seguida, 
são explicitados os processos metodológicos para o desenvolvimento deste trabalho, e, por fim, trazemos os resultados obtidos, a análise desses resultados, e nossas considerações finais. 


\section{A pretônica / $/$ em estudos variacionistas recentes}

A variação das pretônicas /E/ e /O/ é um fenômeno que vem despertando ultimamente pesquisas e discussões sob 0 prisma da Sociolinguística Variacionista (LABOV, 2008; WEINREICH; LABOV; HERZOG, 2006), por causa da consequência de variedade dialetal suscitada em nosso vasto país.

Apesar disso, notamos dificuldade na localização de pesquisas relativas ao nosso objeto de investigação que trabalhassem com o mesmo banco de dados (ALECE; ALPB; APFB). Então, decidimos utilizar, como referencial teórico em nossa pesquisa, os estudos que fossem recentes, e que também estivessem fundamentados na Sociolinguística Variacionista (LABOV, 2008; WEINREICH; LABOV; HERZOG, 2006) além de tratarem da variação da pretônica $/ O /$, independente do banco de dados utilizado, desde que fosse de Atlas brasileiros. Seguindo esses parâmetros, selecionamos as pesquisas de Paim e Anjos (2015), Carmo e Tenani (2013), Cruz e Souza (2013) e Razky, Lima e Oliveira (2012), das quais explicitaremos os resultados sobre a pretônica /O/ a seguir.

O primeiro estudo que apresentaremos pertence aos pesquisadores Paim e Anjos (2015). Eles realizaram uma pesquisa de natureza variacionista acerca do comportamento das vogais médias altas $[\mathrm{m}]$ e $[\square]$, médias baixas [Ð] e [2] e altas [H] e [४] em contexto pretônico, observando o banco de dados do Atlas Linguístico do Brasil (ALiB). Além do embasamento teórico metodológico da Sociolinguística Variacionista, os pesquisadores recorreram a abordagem da Dialetologia Pluridimensional. Para uma análise estatística, os dados dessa pesquisa foram submetidos ao programa Goldvarb 2001.

A amostra analisada é composta de oito inquéritos de informantes soteropolitanos e divididos em três variáveis independentes: faixas etárias (faixa 1 - de 18 a 30 anos; faixa 2 - de 50 a 65 anos), sexo (feminino e masculino) e nível de escolaridade (fundamental e universitário). A variável dependente desta pesquisa é o alçamento vocálico pretônico, do qual destacaremos os resultados relativos à variante alta $[\bullet]$. 
Os resultados demonstraram primeiramente que há uma predominância da variante [2] revelando uma frequência de $57,8 \%$, seguida da variante [ $\bullet$ ] com uma frequência de $24,9 \%$ e da variante [ $[$ ] com $17,3 \%$. Com relação à faixa etária, a vogal alta posterior [ $\bullet$ ] apresentou um peso relativo (doravante PR) de 0.63 para a faixa 2 (50-65 anos) que superou a faixa 1 (18-30 anos) com PR de 0.34 , evidenciando o constante uso do alteamento [ $\bullet$ ] pelo grupo de informantes mais velhos.

Já o fator sexo não se mostrou estatisticamente válido, por isso, foi realizado um cruzamento dos fatores escolaridade e sexo. A vogal alta posterior pretônica [ - obteve maior destaque no uso pelos informantes do nível fundamental, não apresentando tanta relevância o fator sexo, pois tanto homens quanto mulheres deste nível apresentaram, respectivamente, um PR de 0.58 e 0.56 .

Os números apresentados nos resultados mostraram que a regra de abaixamento [2] destaca-se sobre a de alçamento [ $\boldsymbol{*}$ ], porém, diante dos fatores idade e escolaridade, o processo de alçamento [ $\bullet$ tornou-se mais evidente.

O segundo estudo que apresentaremos pertence às pesquisadoras Carmo e Tenani (2013). Elas analisaram o comportamento variável das vogais médias pretônicas / $/ \mathrm{m} /$ e / $\square /$ do noroeste paulista a partir de uma amostra de 38 entrevistas do banco de dados IBORUNA do Projeto Amostra Linguística do Interior Paulista (ALIP), utilizando como fundamentação teórica a Teoria da Variação e Mudança Linguística (LABOV, 2008). Os dados foram submetidos ao processamento estatístico pelo programa Goldvarb X.

A amostra investigada é constituída de 38 entrevistas realizadas à 152 informantes da região do noroeste paulista. Essas entrevistas compõem a Amostra Censo que pertencente ao banco de dados IBORUNA do ALIP. A realização e a não realização do alçamento vocálico pretônico [ a variável dependente desta pesquisa.

Os fatores sociais considerados na possível variação foram sexo (masculino e feminino); faixa etária (de 7 a 15 anos; de 16 a 25 anos; de 26 a 
35 anos; de 36 a 55 anos e acima de 55 anos) e escolaridade (Ensino Fundamental I e II; Ensino Médio e Ensino Superior).

Inicialmente, foi realizada uma rodada geral englobando todas as ocorrências. No geral, os resultados sobre a aplicação da regra de alçamento vocálico pretônico mostraram um valor de $83,7 \%$ para não realização do alçamento vocálico pretônico contra 16,3\% para a realização do alçamento vocálico pretônico. Nessa rodada, a variável social que apresentou maior relevância no programa estatístico foi o fator sexo/gênero. A variável faixa etária não apresentou, no programa estatístico, os resultados relevantes, por isso, foi descartada pelas pesquisadoras.

As variáveis sociais mostraram-se pouco relevantes. 0 processo de alçamento [ ] é pouco beneficiado pelo fator sexo masculino, apresentando um PR de 0.543. Já o sexo feminino mostrou-se ser pouco desfavorecedora, pois apresentou um PR de 0.459. A faixa etária e a escolaridade não foram selecionadas como fator relevante para a aplicação do alçamento [ $\bullet$, indicando que o fenômeno encontra-se em variação estável.

O terceiro estudo que apresentaremos pertence aos estudiosos Cruz e Souza (2013). Eles investigaram a variação vocálica das médias pretônicas no português falado em Belém do Pará. Embasados na Sociolinguística Variacionista de Labov (1972), analisaram uma amostra de 48 entrevistas selecionadas do banco de dados do Projeto Norte Vogais (CRUZ, 2012). A amostra encontra-se estratificada nas variáveis sociais faixa etária (de 15 a 25 anos; de 26 a 45 anos e 46 anos em diante), sexo (masculino e feminino) e escolaridade (não escolarizados, ensinos Fundamental, Médio e Superior). A variável dependente é a manutenção, o alteamento e o abaixamento das vogais médias pretônicas $[m, \square]$. Os dados coletados foram submetidos à análise estatística pelo pacote de programas Varbrul.

Os resultados revelaram que a aplicação da manutenção vocálica pretônica é predominante no falar belenense, pois os PRs apresentados foram de 0.819 para vogais médias fechadas [m, 口], de 0.124 para vogais altas [H茾 ] e de 0.057 para vogais médias abertas [ [2] 
Nos fatores sociais, a variável escolaridade mostrou que os informantes com nível fundamental tendem a fazer mais uso da vogal média pretônica [ $\square]$, pois apresentou um PR de 0.61. Já com relação à faixa etária, a variável que revelou ser mais beneficiadora da aplicação da manutenção [ $[\square]$ foi a primeira faixa (de 15 a 25 anos).

Por último, Razky, Lima e Oliveira (2012), a partir do corpus Atlas Linguístico Sonoro do Pará (ALISPA), analisaram, em 40 informantes, 1008 dados referentes à pretônica /m/ na perspectiva dialetológica. Os fatores sociais observados foram: a localidade (Abaetetuba, Altamira, Belém, Bragança, Breves, Cametá, Conceição do Araguaia, Itaituba, Marabá e Santarém), a faixa etária (19-30 e 40-70) e o sexo (masculino e feminino). Os dados gerais dos autores foram de $23 \%$ para o alteamento [ $\bullet$ ], 51\% para a manutenção [ $\square$ ], e $26 \%$ para o abaixamento [2], mostrando que no Pará, a regra mais frequente é a de manutenção.

As variáveis analisadas pelos autores foram apresentadas em gráficos que não continham legendas de valores, dessa forma, apresentaremos as interpretações deles para cada gráfico de cada variável. Para a variável localidade, em todas as cidades, a diferença entre [0] e [2] foi bastante significativa para a variante fechada $[\square]$, dessa forma, essa variante foi predominante em todas as cidades paraenses.

Quanto à variável faixa etária, a frequência de dados também evidencia a predominância de [ $\square$ ] na faixa etária mais jovem (19-30) e na mais velha (40-70). Aqui, temos os resultados mais próximos entre as variantes avaliadas, ou seja, os dados da primeira e da segunda faixa etária são praticamente idênticos, dessa forma, os mais velhos e os mais jovens usam, em ordem decrescente de preferência, $[\square],[\boldsymbol{Q}]$ e $[\boldsymbol{\bullet}]$.

Para a variável sexo, as maiores frequências, correspondem também à variante fechada [ $[$ ]. Os autores perceberam que o comportamento linguístico dos dois sexos se aproxima nas as três variantes: mais aproximação para [0], vindo depois $[\bullet]$ e, em seguida, $[\square]$. 
Vejamos a seguir, no Gráfico 1, um resumo das frequências gerais de cada um dos estudos trazidos por nós, para que tenhamos um panorama da variação em tela.

Gráfico 1 - Percentual de uso de cada variante de /O/ em cada um dos estudos citados

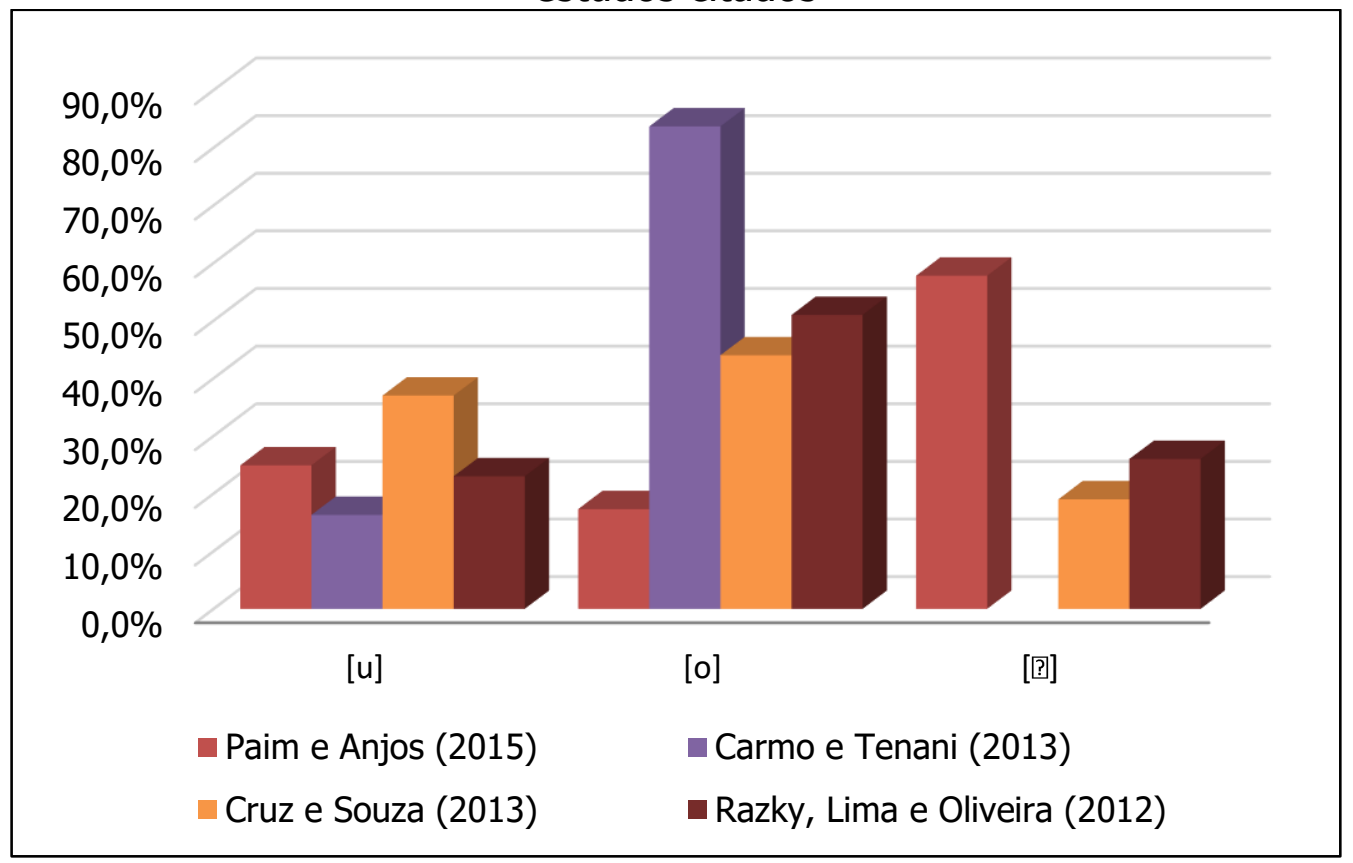

Fonte: elaboração própria.

Podemos observar no gráfico 1 que, no estudo de Carmo e Tenani (2013), a aplicação de manutenção da vogal média pretônica [ $\square$ ] possui o maior percentual $(83,7 \%)$, ou seja, os dados investigados revelaram que os falantes do interior paulista fazem mais uso da variante fechada [ $\square$ ]. Em seguida, podemos perceber no mesmo gráfico que a pesquisa de Paim e Anjos (2015) possui o segundo maior percentual de 57,8\% para a aplicação de abaixamento [2], revelando que os dados do Atlas Linguístico do Brasil (ALiB) possuem uma maior representatividade da variante aberta [2]

Porém, as pesquisas de Cruz e Souza (2013) e Razky, Lima e Oliveira (2012) apresentaram, respectivamente, os percentuais mais baixos de $19 \%$ e 26\% para a aplicação da regra de abaixamento [2], revelando que os falantes do Pará não fazem uso da variante aberta [2]. Já, para a aplicação da regra de 
alçamento [ $\bullet$, podemos perceber que os estudos apresentam porcentagens aproximadas, pois, para o uso dessa variante, no estudo de Cruz e Souza (2013), encontramos um percentual um pouco mais elevado (37\%) em relação aos estudos de Paim e Anjos (24,9\%), Razky, Lima e Oliveira (23\%) e Carmo e Tenani $(16,3 \%)$, representando pouca aplicabilidade da variante alta [ $\bullet$.

$\mathrm{Na}$ seção seguinte, apresentaremos uma breve explanação sobre os pressupostos da Sociolinguística Variacionista, teoria base de nossa pesquisa.

\section{Sociolinguística variacionista}

O sociolinguista Labov desenvolveu pesquisas demonstrando que a língua é um sistema heterogêneo e que tem caráter evolutivo dentro do âmbito social e histórico. A partir de sua renomada pesquisa sobre a comunidade da ilha Martha's Vineyard, em Massachusetts, EUA, Labov desenvolveu, segundo Alkmim (2002, p. 30), "um modelo de descrição e interpretação do fenômeno linguístico no contexto social de comunidades urbanas". Labov sistematizou a variação existente na língua da comunidade de fala vineyardense, relacionando os fatores externos à língua como, por exemplo, idade, sexo, ocupação, dentre outros fatores que influenciam a forma de pronunciar as palavras de uma língua.

Em outro estudo, o sociolinguista americano relacionou variantes fonéticas de acordo com as estratificações sociais em sua pesquisa em lojas de Nova Iorque e percebeu que as realizações do fonema / $\square$ / eram baseadas na camada social a qual os funcionários pertenciam. Ou seja, quanto mais baixa a classe dos funcionários, menos frequente o uso do fonema $/ \square /$, indicando a influência dos níveis sociais dos falantes nas formas de se expressarem. De acordo com Labov (2008, p. 238):

A existência de variação e de estruturas heterogêneas nas comunidades de fala investigadas está certamente bem fundamentada nos fatos. É a existência de qualquer outro tipo de comunidade de fala que deve ser posta em dúvida. (...). Tão logo 
eliminarmos a suposta associação entre estrutura e homogeneidade, estaremos livres para desenvolver os instrumentos formais necessários para lidar com a variação inerente dentro da comunidade de fala.

Podemos perceber que está presente na convivência social, uma pluralidade linguística na fala, denominada de variedades linguísticas. Essas inúmeras variedades utilizadas por uma comunidade constituem o chamado repertório linguístico.

Segundo Mollica (2003, p. 10), "A variação linguística constitui fenômeno universal e pressupõe a existência de formas linguísticas alternativas denominadas variantes", as variantes são as formas que estão em concorrência, mas que possuem o mesmo significado. Conforme Tarallo (1986, p. 8), são "diversas maneiras de se dizer a mesma coisa em um mesmo contexto, e com o mesmo valor de verdade. A um conjunto de variantes dá-se o nome de variável linguística".

Labov combinou fatos linguísticos com fatos sociais que havia percebido sobre a ilha americana e defende em seus trabalhos sociolinguísticos, que a variação linguística não é livre e sem restrições, que a variabilidade intraespacial reflete e constrói uma oposição social entre falantes. A diferenciação linguística parece servir ao propósito da diferenciação social. A combinação de fatos linguísticos sobre os falantes mais antigos e os mais jovens e uma análise das mudanças sociais que ocorreram em Vineyard simulou um quadro de como as mudanças sociais e linguísticas funcionam através da comunidade com a passagem do tempo (MEYERHOFF, 2006, p. 8-26).

Labov defende, dessa forma, que a linguística não pode ser, se não, social, afirmando que "resistiu ao termo sociolinguística" por anos, pois, o termo implicaria em haver uma teoria linguística que não fosse social. Muitos linguistas tinham se voltado para o estudo da própria fala e não para a fala em uso, no dia-a-dia dos falantes com seus familiares, amigos e no trabalho, onde a língua é realmente usada (LABOV, 2008, p. 13). 
Partindo da necessidade de verificar a variação linguística em plena atividade é que a sociolinguística se utiliza de uma metodologia que busca bancos de dados de fala espontânea, ou semi-espontânea, para análise de fenômenos da língua e se utiliza, ainda, de testagem estatística desses dados de fala para verificar quais fatores beneficiam uma ou outra variante.

Para esta pesquisa, analisaremos o comportamento da variável dependente vogal média posterior pretônica $/ O /$, observando suas três variantes concorrentes: a vogal média alta [0], a vogal média baixa [2] e a vogal alta $[\diamond]$, à luz do aporte teórico-metodológico da Sociolinguística Variacionista, com o objetivo de verificarmos com se dá a variação em questão a partir das variáveis sociais em dados dos atlas da Bahia, Ceará e Paraíba.

\section{Metodologia}

Para realizarmos essa pesquisa, analisamos dados provenientes de Atlas Linguísticos brasileiros que "se preocupam em descrever as variantes mais significativas da língua falada nas diversas localidades, seja zona urbana, seja zona rural, levando em conta as variáveis sexo, faixa etária, escolaridade, registros, etc" (VIEIRA, 1999, p. 256-266). Destacamos, dessa forma, a importância desses bancos de dados da dialetologia para pesquisas que venham a contribuir com um retrato sociolinguístico do falar brasileiro.

Como já explanamos, o aporte teórico metodológico que embasou nossa pesquisa é a Sociolinguística Variacionista (LABOV, 2008; WEINREICH; LABOV; HERZOG, 2006) e, sob essa teoria, analisamos os bancos de dados dos corpora Atlas Linguístico do Estado do Ceará (BESSA, 2010), Atlas Linguístico da Paraíba (ARAGÃO; MENEZES, 1984) e Atlas Linguístico dos Falares Baianos (ROSSI; ISENSÉE; FERREIRA, 1963). As cartas fonéticas desses atlas que apresentam a realização das vogais média alta $[\square]$, média baixa [0] e alta [ $[$ ] em contexto pretônico foram selecionadas para essa investigação.

Nossa amostra é constituída no total de 472 informantes desses três atlas, sendo 265 informantes no Atlas Linguístico do Estado do Ceará, 107 
informantes no Atlas Linguístico da Paraíba e 100 informantes no Atlas Prévio dos Falares Baianos. O perfil dos informantes é diferente entre os atlas, por isso, decidimos controlar os fatores sociais sexo (masculino e feminino), faixa etária (faixa 1 - de 20 a 60 anos e faixa 2 - acima de 60 anos), escolaridade (não alfabetizados e alfabetizados) e localidade (Ceará, Paraíba e Bahia).

Importante explicitarmos que as idades destes informantes nos atlas analisados apresentam-se muito discrepantes, tendo em vista que a variação das faixas etárias, nos Atlas analisados, vai de 25 a 84 anos de idade, o que dificultou a distribuição equitativa dos informantes por faixas etárias. Dessa maneira, os informantes foram distribuídos em duas faixas etárias que guardam intervalos bastante amplos, em se tratando de estudos linguísticos: a primeira vai de 20 a 60 anos, e a segunda vai de 61 anos em diante. Temos, assim, uma diferença de 40 anos entre a faixa 1 e a faixa 2.

O primeiro atlas observado foi o Atlas Linguístico do Ceará - ALECE, no qual selecionamos um total de 34 cartas fonéticas que apresentassem a variação da vogal média pretônica $/ 0 /$. As cartas são identificadas por números e palavras para a realização fonética. Nesse atlas, selecionamos as cartas 10 (trovoada); 27, 28, 37, 38 (temporal); 43 (relâmpago); 47 (poluída); 50 (poluída e toldada); 53 (impotável e nojenta); 55 (poluída); 58, 59 (corrupio); 63 (pororoca); 64 (porão); 69 (corrente); 72, 73 (orvalho); 99 (cometa); 102 (trovão); 164 (adotivo); 165 (ignorado e sozinho); 166 (adotivo); 168 (jogado); 187, 188 (orelha); 195, 196 (cotovelo); 199 (tornozelo); 203, 204 (tornozelo e mocotó); 209 (tornozelo); 211 (tornozelo e mocotó); 215 (cotovelo) 232 (bochecha).

O segundo atlas observado foi o Atlas Linguístico da Paraíba - ALP, no qual selecionamos um total de 10 cartas fonéticas com a transcrição das variações da vogal média pretônica /O/. As cartas selecionadas foram 27 (orvalho); 29 (mormaço); 53 (corpete); 84 (sovina); 119 (bacorinho); 120 (porquinho); 122 (cortiço); 125 (borboleta); 134 (torrado); 136 (corrimboque).

No Atlas Prévio dos Falares Baianos - APFB, selecionamos as cartas 9 (trovoada); 35 (rodete); 36 (moleque); 39 (moranga); 46 (porcelana); 52 
(torrado); 62 (bolacha); 63 (mocotó, tornozelo e cotovelo); 70 (torneira); 74 (costura); 75 (opado); 108 (prostituta); 117 (poleiro); 131 (borrego), somando um total de 14 cartas selecionadas para a coleta das transcrições fonéticas.

Após a seleção das cartas, coletamos as transcrições fonéticas, identificando-as com as seguintes informações: atlas de origem, número da carta, palavra título para transcrição, ponto/localidade, informante, sexo, idade, escolaridade e a transcrição fonética.

Em seguida, codificamos os dados coletados, utilizando os símbolos do teclado do computador. Para a cadeia de codificação utilizamos inicialmente os símbolos o (variante vogal média alta), u (variante vogal alta) e $\mathbf{0}$ (variante vogal média baixa) para identificarmos as realizações variáveis da vogal média pretônica /O/. Já para identificar o perfil do informante, utilizamos os símbolos m (masculino) e f (feminino) correspondentes ao sexo; faixas $\mathbf{1}$ (de 20 a 60 anos) e $\mathbf{2}$ (acima de 60 anos) correspondentes à idade; nível de escolaridade $\mathbf{n}$ (não alfabetizados) e a (alfabetizados). Por fim, para identificar a área geográfica, utilizamos os símbolos c (Ceará), p (Paraíba) e b (Bahia). Codificamos 1246 realizações variáveis da vogal média pretônica /o/ no Atlas Linguístico do Ceará, 156 no Atlas Linguístico da Paraíba e 472 no Atlas Prévio dos Falares Baianos.

Após a digitação do material codificado, os dados foram submetidos ao processamento estatístico do programa Goldvarb X (SANKOFF; TAGLIAMONTE; SMITH, 2005), o qual aponta por ordem de relevância e em perspectiva estatística os condicionadores que mais influenciam a realização das variantes [प⿴囗十) além de permitir a combinação de dois ou mais fatores dentro de um grupo de fatores.

\section{Análise dos dados}

O total de ocorrências obtidas nos três Atlas analisados foi de 1874 dados, distribuídos assim: 472 dados $(25,2 \%)$ oriundos do APFB, 156 dados $(8,3 \%)$ do ALP e 1246 dados (66,5\%) do ALECE. 
Gráfico 2 - Frequência geral da vogal /O/ nos três Atlas linguísticos estaduais

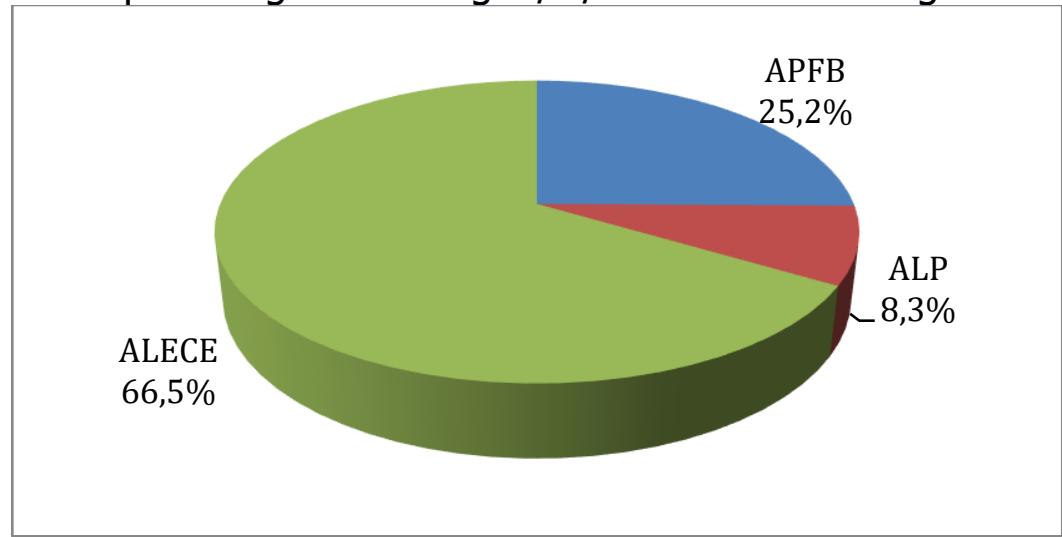

Fonte: elaboração própria.

A partir desses dados gerais, dispostos no Gráfico 2, traçaremos, nas seções seguintes, os resultados encontrados para a regra de abaixamento e de alteamento da vogal média pretônica $/ \mathrm{O}$.

\section{Abaixamento}

O Gráfico 3 trata dos índices totais de aplicação do abaixamento da pretônica /O/ em relação à manutenção, conforme podemos observar a seguir.

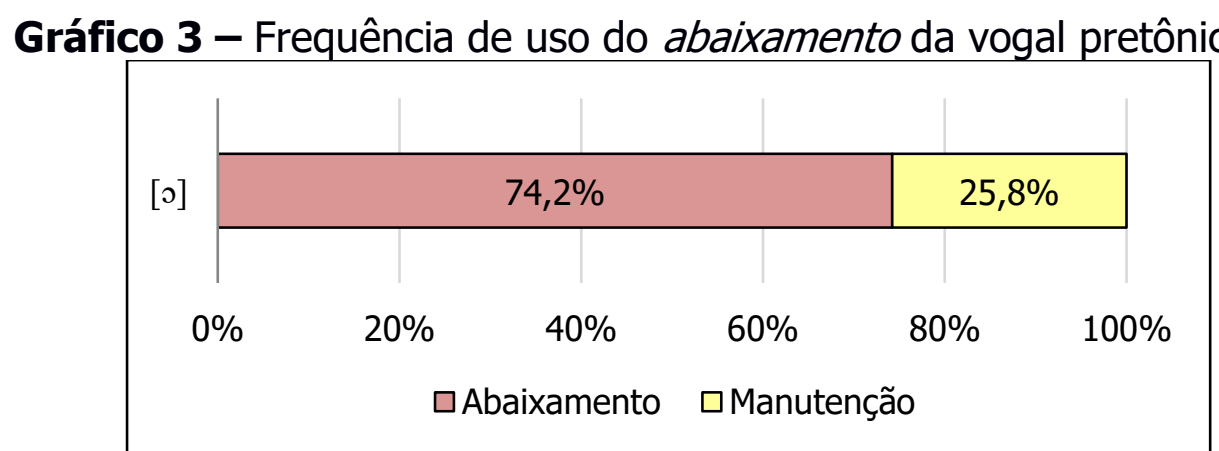

Fonte: elaboração própria. 
O Gráfico 3 indica, inicialmente, que, nos dados coletados nos três estados, predomina o abaixamento em detrimento da manutenção de $/ O /$, uma vez que encontramos 642 dados de abaixamento $(74,2 \%)$ e 223 dados de manutenção $(25,8 \%)$. Comparando a nossa frequência de abaixamento com a dos estudos apresentados em nossa revisão da literatura, vemos que apenas os resultados de Paim e Anjos (2015), com dados de soteropolitanos, com frequência de 57,8\%, se assemelham aos nossos. Já Razky, Lima e Oliveira (2012) apresentaram dados de paraenses, com frequência de $26 \%$ para a regra de abaixamento [2], e Cruz e Souza (2013), com dados também referentes aos falantes paraenses retirados de outro banco de dados, apresentaram um percentual de $19 \%$ o abaixamento [2].

De qualquer forma, as frequências, para o abaixamento, nos três estados analisados, são muito superiores às pesquisas citadas: Bahia com $77,9 \%$, Ceará com $71,3 \%$ e Paraíba com $82,7 \%$.

$\mathrm{Na}$ busca de variáveis relevantes para a regra de abaixamento, na rodada para a variante aberta [2], o programa estatístico Goldvarb X selecionou, como relevantes, duas variáveis: localidade e escolaridade, como podemos ver na Tabela 1 abaixo. 
Tabela 1 - Atuação da variável localidade para o abaixamento de /O/

\begin{tabular}{c|c|c|c}
\hline Fator & Aplicação/Total & \% & Peso Relativo \\
\hline Bahia & $166 / 213$ & $77,9 \%$ & $\mathbf{0 . 5 4 8}$ \\
\hline Ceará & $395 / 554$ & $71,3 \%$ & 0.460 \\
\hline Paraíba & $81 / 98$ & $82,7 \%$ & $\mathbf{0 . 6 2 0}$ \\
\hline
\end{tabular}

Input 0.745 - Significance $=0.019$

Fonte: elaboração própria.

Observando a Tabela 1, constatamos que a Paraíba, com 0.620 de PR, é o estado que mais favorece o abaixamento da vogal média pretônica /O/ e, em segundo lugar, aparece a Bahia, com PR de 0.548 , pouco acima do ponto de neutralidade. Já o estado do Ceará, com PR de 0.460 , inibe a aplicação desta.

Ainda sobre o processo de abaixamento, decidimos criar novos grupos de fatores a partir da variável localidade: localidade vs. sexo; localidade vs. faixa etária; e localidade vs. escolaridade, e realizamos uma nova rodada dos dados. Nessa nova rodada, o Goldvarb X selecionou como relevante para 0 abaixamento de /O/ o grupo de fatores localidade vs. faixa etária, como podemos ver no Gráfico 4 abaixo.

Gráfico 4 - Atuação da variável escolaridade vs. faixa etária para o abaixamento de /O/

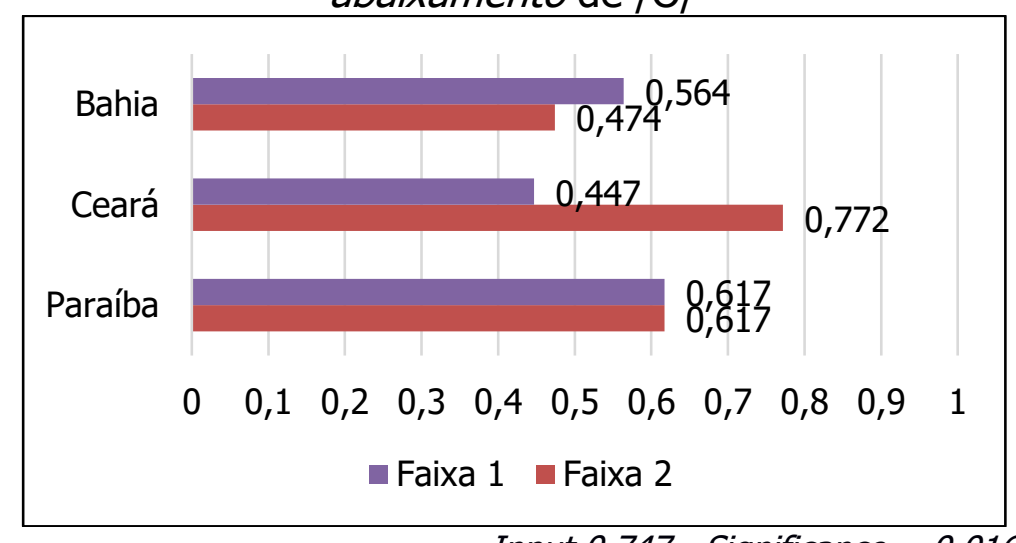

Fonte: elaboração própria.

Input 0.747 - Significance $=0.016$

Podemos perceber que os informantes baianos de faixa 1, paraibanos de ambas as faixas e cearenses de faixa 2, privilegiam o abaixamento da vogal 
pretônica posterior /O/, conforme revelam os PRs de $0.564,0,617,0,617$ e 0,772 , respectivamente, para estes fatores.

Já, para os informantes baianos de faixa 2e cearenses de faixa 1, os PRs apresentados foram de 0.474 , e 0,447, respectivamente, revelando que esses informantes não influenciam na aplicação da vogal pretônica média aberta [2]. Se a primeira faixa etária não guardasse um intervalo tão grande, quarenta anos, diríamos que poderia haver indícios de que o abaixamento de /O/ represente um caso de processo de mudança na Paraíba, uma variação estável no Ceará e uma possível mudança em progresso na Bahia, como preconizam Weinreich, Labov e Herzog (2006), quando dizem que a faixa etária dos mais jovens pode dar início a uma mudança em curso na variação linguística, mas em nosso caso, os indivíduos da faixa I são informantes de 20 a 60 anos, ou seja, o que não nos permite afirmar qualquer informação relacionada à faixa etária.

Passemos agora, para a análise dos dados da regra de alteamento nos dados dos três atlas analisados nesta pesquisa.

\section{Alteamento}

A frequência da regra de alteamento em nossa pesquisa apresentou uma quantidade maior de dados que a regra de abaixamento, pois foram identificados 1232 dados totais, sendo 1009 correspondentes a 81,9\% de alteamento e 223 dados que correspondem a 18,1\% de manutenção. Os índices de aplicação do alçamento da vogal pretônica /O/ podem ser observados nos dados do Gráfico 5 a seguir. 


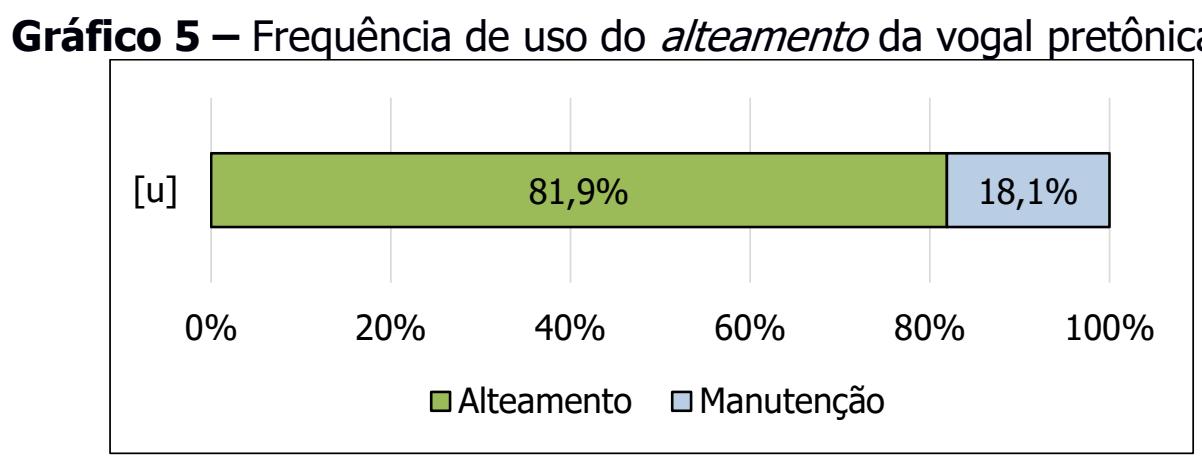

Fonte: elaboração própria.

Comparando nossas frequências para a regra de alteamento [ $\bullet$ com as frequências de Paim e Anjos (2015), Carmo e Tenani (2013), Cruz e Souza (2013) e Razky, Lima e Oliveira (2012), verificamos que os belenenses, paraenses, soteropolitanos e paulistanos apresentam frequências bastante inferiores às de nosso estudo com $16,3 \% 23 \%, 24,9 \%$ e $37 \%$ de alteamento, respectivamente, contrapondo-se ao nosso com frequência de $81,9 \%$.

Seguindo nossa análise após as frequências, continuamos com a utilização do Goldvarb X para obtermos as variáveis estatisticamente relevantes para o alteamento de $/ \mathrm{O}$. Na análise binária, o programa selecionou como relevante apenas uma variável: a escolaridade. Vejamos na Tabela 2 os resultados apresentados para essa variável.

Tabela 2 - Atuação da variável escolaridade para o alteamento de /O/

\begin{tabular}{c|c|c|c}
\hline Fator & Aplicação/Total & $\%$ & Peso Relativo \\
\hline Não alfabetizados & $592 / 669$ & $84,7 \%$ & $\mathbf{0 . 5 4 6}$ \\
\hline Alfabetizados & $417 / 533$ & $78,2 \%$ & 0.439 \\
\hline
\end{tabular}

Input 0.821 - Significance $=0.006$

Fonte: elaboração própria.

Os dados revelam que o fator escolaridade favorece o processo de alçamento da vogal média alta posterior pretônica $/ O /$. Os índices mostraram que os informantes não alfabetizados tendem a fazer mais uso da vogal pretônica alta $[\diamond]$, pois apresentou um PR de 0.546 e uma frequência de $84,7 \%$. Já com os informantes alfabetizados, a rodada estatística mostrou um 
PR de 0.439 e uma frequência de $78,2 \%$, revelando que esses informantes desfavorecem a aplicação do alçamento da vogal pretônica $/ O /$.

A literatura sociolinguística acredita que a variável escolaridade seja forte influenciadora das variantes de prestígio, dessa forma, como o alteamento de /O/ gera uma variante estigmatizada socialmente como em cotovelo $c[\diamond]$ tuvelo, bolacha $\sim b[\diamond]$ lacha e sovina $\sim s[\diamond]$ vina, acreditamos que os alfabetizados, por terem maior contato com a escola, que é responsável pela preservação das variantes de prestígio, sejam inibidores da regra de alteamento. Essa afirmação sobre a escolaridade não foi criada de forma aleatória, pois, sabemos que:

[...] a escola gera mudanças na fala e na escrita das pessoas que as frequentam e das comunidades discursivas. Constata-se, por outro lado, que ela atua como preservadora de formas de prestígio, face a tendências de mudança em curso nessas comunidades (VOTRE, 2004, p. 51).

Assim, verificamos que os não alfabetizados são aqueles indivíduos que favorecem a variante $[\bullet]$, por serem falantes com nenhum ou pouquíssimo contato com os bancos escolares, com a norma padrão da língua e, consequentemente, mais vulneráveis às variantes socialmente estigmatizadas.

Já o fator sexo não se mostrou relevante na aplicação das regras de abaixamento e nem de alçamento da pretônica /O/, em nosso estudo, pois não foi selecionada em nenhuma das análises do Goldvarb X, corroborando com os estudos de Paim e Anjos (2015). Já para Cruz e Souza (2013), os menos escolarizados se mostraram favorecedores do processo de manutenção [ $\square]$.

$\mathrm{Na}$ tentativa de conhecermos mais ainda de nosso fenômeno, realizamos outras rodadas no programa computacional, contemplando os dados dos estados de forma separada. Dessa forma, realizamos mais três rodadas: com dados do Ceará, com uma variável relevante; com dados da Bahia, que não selecionou fatores relevantes; e com dados da Paraíba que, assim como a Bahia, não obteve fatores selecionados pelo Goldvarb X. 
Isto posto, para o Ceará, o Goldvarb X selecionou a variável escolaridade como relevantes para a realização do alteamento de $/ O /$, como podemos ver sua atuação na tabela 3 .

Tabela 3 - Atuação da variável escolaridade para o alteamento de /O/ no

Ceará

\begin{tabular}{c|c|c|c} 
Fator & Aplicação/Total & \% & Peso Relativo \\
\hline Não alfabetizados & $315 / 368$ & $85,6 \%$ & $\mathbf{0 . 5 7 2}$ \\
\hline Alfabetizados & $377 / 438$ & $78,1 \%$ & 0.445
\end{tabular}

Input 0.816 - Significance $=0.007$

Fonte: elaboração própria.

Podemos ver na tabela 2 o fator não alfabetizados beneficia o processo de alçamento de $/ 0 /$. Os pesos relativos desta tabela mostram que os cearenses não alfabetizados tendem levemente a fazer mais uso da variante vogal alta [ ] $(0.572)$, com uma frequência de $85,6 \%$. Para os cearenses alfabetizados, a análise estatística mostrou um PR de 0.445 e uma frequência de $78,1 \%$, nos mostrando que esses informantes fazem menos uso do alçamento da vogal pretônica $/ 0 /$.

Esses dados corroboram com os apresentados na Tabela 2, onde os analfabetos dos três estados também beneficiam a regra de alteamento de $/ 0 /$. Infelizmente, não foi possível verificarmos a atuação desta variável separadamente nos estados da Bahia e da Paraíba, mas podemos saber que "o nível de escolaridade [...] continua a desempenhar um papel crítico na configuração geral do domínio da língua padrão pelos informantes." (VOTRE, 2004, p. 56).

\section{Conclusão}

Em nossa pesquisa, notamos que as variáveis extralinguísticas podem influenciar na aplicação dos processos de alçamento, abaixamento e manutenção da vogal média alta posterior pretônica $/ O /$. 
Nossa hipótese sobre os informantes não alfabetizados fazerem uso da variante alta [ ] se confirmou em nossa pesquisa, tanto de um modo geral, como em especial para os dados do Ceará. Já as hipóteses do fator sexo não se confirmaram, pois, este fator não foi apontado como relevante no processo de alçamento e abaixamento. Confirmou-se, também, que a variável social localidade influencia na realização da variante aberta [0] em relação à variante [ם]. Para a faixa etária, apenas os mais idosos do Ceará e da Paraíba apresentaram-se beneficiadores do abaixamento.

Dessa forma, ao analisarmos os fatores sociais em dados de atlas dos estados da Bahia, Ceará e Paraíba, chegamos a resultados que apresentam o alteamento favorecido pelos falantes não alfabetizados, enquanto que o abaixamento é favorecido pela localidade Bahia e Paraíba e pela faixa etária de indivíduos de 20 a 60 anos da Paraíba e acima de 60 anos na Paraíba e Ceará.

Acreditamos que ainda há muito para ser pesquisado quanto à variação das vogais médias pretônicas posteriores no Brasil, tanto em relação a outras variáveis, como a outros bancos de dados. Dessa forma, nosso estudo se trata de um retrato variacionista desse fenômeno, que ao lado de outros estudos, pode montar uma fotografia bem mais detalhada da língua portuguesa falada em nosso país.

\section{Referências}

ALKMIM, Tânia Maria. Sociolingüística: parte 1. In: MUSSALIM, Fernanda; BENTES, Anna Christina (Org.). Introdução à lingüística: domínios e fronteiras. São Paulo: Cortez, 2002. v. 1. p. 21-47.

ARAGÃO, Maria do Socorro Silva de; MENEZES, Cleusa Palmeira Bezerra de. Atlas Linguístico da Paraíba. Brasília: Universidade Federal da Paraíba/CNPq, 1984. v. $1,2$.

BESSA, José Rogério Fontenele (Coord.). Atlas linguístico do Ceará. Universidade Federal do Ceará. Fortaleza: Edições UFC, 2010. v. 1, 2. 
CARMO, Márcia Cristina do; TENANI, Luciani Ester. As vogais médias pretônicas na variedade do noroeste paulista: uma análise sociolinguística. Alfa: Revista de Linguística, São José do Rio Preto, v. 57, n. 2, p. 607-637, 2013.

CRUZ, Regina. Vogais na Amazônia Paraense. Alfa: Revista de Linguística, Araraquara, v. 56, p. 945-972, 2012.

CRUZ, Regina; SOUSA, Josivane. Variação vocálica das médias pretônicas no português falado na cidade de Belém (PA). Letrônica, Porto Alegre, v. 6, n. 1, p. 26-46, 2013.

LABOV, William. Padrões sociolinguísticos. Tradução: Marcos Bagno; Maria Marta Pereira Scherre; Caroline Rodrigues Cardoso. São Paulo: Parábola Editorial, 2008.

MEYERHOFF, Miriam. Introducing sociolinguistics. London: Routledge, 2006. Disponível em:

<http://home.lu.Iv/ pva/Sociolingvistika/0891160_FFF6C_meyerhoff_miriam_in troducing_sociolinguistics.pdf >. Acesso em: 23 jan. 2018.

MOLLICA, Maria Cecília. Fundamentação teórica: conceituação e delimitação. In: MOLLICA, Maria Cecília; BRAGA, Maria Luiza (Org.). Introdução à sociolinguística: o tratamento da variação. São Paulo: Contexto, 2003. cap. 1.

PAIM, Marcela Moura Torres; ANJOS, Vitor Meneses dos. O alçamento das vogais médias pretônicas em Salvador (BA). Caderno de Letras, Pelotas, n. 24, jan./jun. 2015. Disponível em:

<https://periodicos.ufpel.edu.br/ojs2/index.php/cadernodeletras/article/downlo ad/7297/5110>. Acesso em: 23 jan. 2018.

RAZKY, Abdelhak; LIMA, Alcides Fernandes de; OLIVEIRA, Marilúcia Barros de. As vogais médias pretônicas no falar paraense. Signum: Estudos da Linguagem, Londrina, v. 15, n. 1, p. 293-310, 2012. Disponível em:

<http://www.uel.br/revistas/uel/index.php/signum/article/view/11703>. Acesso em: 23 jan. 2018.

ROSSI, Nelson; ISENSÉE, Dinah Maria; FERREIRA, Carlota. Atlas prévio dos falares baianos. Rio de Janeiro: INL, 1963.

SANKOFF, David; TAGLIAMONTE, Sali A.; SMITH, Eric. Goldvarb X: a variable rule application for Macintosh and Windows. Toronto: Department of Linguistics; Ottawa: Department of Mathematics, 2005. Disponível em: <http://individual.utoronto.ca/tagliamonte/Goldvarb/GV_index.htm\#ref>. Acesso em: 10 jun. 2017.

TARALLO, Fernando. A pesquisa sociolinguística. São Paulo: Ática, 1986. 
VIEIRA, Hilda Gomes. Importância do atlas lingüístico para o ensino/aprendizagem da escrita na escola. Estudos Lingüísticos, São Paulo, v. 28, p. 263-268, 1999. Disponível em: $<$ https://pt.scribd.com/document/239374338/A-Importancia-Do-AtlasLinguistico>. Acesso em: 4 abr. 2018.

VOTRE, Sebastião Josué. Relevância da variável escolaridade. In: MOLLICA, Maria Cecília; BRAGA, Maria Luiza (Org.). Introdução à sociolinguística: o tratamento da variação. São Paulo: Contexto, 2004. p. 51-57.

WEINREICH, Uriel; LABOV, William; HERZOG, Marvin I. Fundamentos empíricos para uma teoria da mudança linguística. Tradução: Marcos Bagno. São Paulo: Parábola Editorial, 2006. 